\title{
Spreminjanje upravljanja javnega potniškega prometa $v$ Sloveniji na podlagi avstrijskih izkušenj
}

UDK: $656.13(497.4)$

\author{
Janez Blaž \\ Ministrstvo za promet, Direkcija RS za ceste \\ janez.blaz@gov.si

\section{Marko Hočevar} \\ Univerza v Ljubljani, Ekonomska fakulteta \\ marko.hocevar@ef.uni-lj.si
}

\section{IZVLEČEK}

Direkcija RS za ceste je kot organ v sestavi Ministrstva za promet upravljalec javnega potniškega medkrajevnega cestnega prometa v Sloveniji. Kot koncedent ima z različnimi avtobusnimi prevozniki - koncesionarji sklenjenih 47 koncesijskih pogodb.

V prispevku je najprej prikazano trenutno stanje na tem področju oziroma obstoječe relacije med koncedentom in koncesionarji in sicer $z$ vidika usklajevanj, dodajanj in ukinjanj voznih redov, zagotavljanja finančnih sredstev kot tudi drugih zadev, ki so sestavni del koncesijskih pogodb.

Izdelane so bile prikazane primerjalne analize z Avstrijo na področju ureditve integriranega, to je mestnega in medkrajevnega cestnega in železniškega javnega potniškega prometa (JPP) in sicer predvsem $z$ vidika učinkovitosti JPP, prikazanega kot število prepeljanih potnikov glede na razpoložljiva finančna sredstva. Predstavljen je 3-nivojski model organizacije integriranega JPP v Avstriji in sistemska razdelitev odgovornosti in pooblastil na teh nivojih.

V nadaljevanju so prikazane aktivnosti na Ministrstvu za promet oziroma Direkciji RS za ceste glede prihodnje ureditve področja javnega potniškega prometa in sicer po I. 2009, ko se iztečejo obstoječe koncesijske pogodbe na tem področju.

Ključne besede: javni potniški promet, Slovenija, Avstrija, koncesije, koncendenti. 
Janez Blaž, Marko Hočevar

Spreminjanje upravljanja javnega potniškega

prometa v Sloveniji na podlagi avstrijskih izkušenj

\section{Trenutno stanje na področju javnega potniškega prometa}

Javni linijski prevoz potnikov se v Republiki Sloveniji od leta 2004 izvaja kot gospodarska javna služba ( $v$ nadaljevanju GJS). Direkcija RS za ceste ( $v$ nadaljevanju DRSC) ima s koncesionarji sklenjenih 47 koncesijskih pogodb. Koncesijske pogodbe so bile sklenjene septembra 2004 in sicer so bile dodeljene neposredno obstoječim prevoznikom, ki so v prometnem letu 2003/2004 opravljali javne linijske prevoze.

Obseg ponudbe izvajanja cestnega primestnega oz. medkrajevnega javnega potniškega prometa (v nadaljevanju JPP) se zmanjšuje. V I. 2004 je bilo prevoženih ca. 51,5 mio. km, v I. 2005 49,5 mio. km, v I. 2006 48,3mio. km. Tudi število prepeljanih potnikov na področju medkrajevnega potniškega cestnega prometa se zmanjšuje. V I. 1985 je bilo prepeljanih več kot 300 mio. potnikov, I. 1995 ca 120 mio., I. 2000 ca. 74 mio., I. 2005 ca. 40 mio. potnikov.

Direkcija RS za ceste, ki je I. 2004 po obstoječi zakonodaji podelila koncesije obstoječim prevoznikom brez razpisa do I. 2008, se srečuje z zahtevami prevoznikov po:

- dodatnem "ukinjanju" nerentabilnih linij;

- izločevanju šolskih prevozov iz sistema javnega potniškega prometa na eni strani, na drugi strani pa združevanju šolskih prevozov $v$ sistem javnega potniškega prometa; zahteve se postavljajo $v$ glavnem $z$ vidika interesov prevoznikov;

- dodatnih finančnih sredstvih v višini ca. 10,4 mio.euro, zaradi (po trditvah prevoznikov) izkazanih izredno visokih stroškov; kot glavni razlog se navaja potrebna razpoložljivost avtobusov ob konicah. Izven konic so avtobusi dejansko "neizkoriščeni", stroški pa ostajajo.

$\checkmark$ poslovanju podjetij obstajajo velike razlike. Na eni strani so podjetja, ki imajo nizke stroške na km (npr.1,07 euro), vendar tudi nadpovprečno nizke prihodke na $\mathrm{km}$ (isto podjetje 0,75 euro)). Na drugi strani so podjetja, ki imajo nadpovprečne prihodke in tudi nadpovprečne stroške (na primer: 1,58 euro) prihodka na $\mathrm{km}$ in 1,92 euro) stroška na $\mathrm{km}$ ). Ob padanju števila potnikov postaja sistem JPP vse dražji, kar pomeni zmanjšanje prihodkov in potrebo po večjih subvencijah (Hočevar, 2007, str. 23 - 37, Hočevar, 2006, str. 89 - 103).

Trenutni sistem javnega potniškega prometa (JPP) temelji na "bruto« modelu, vanj pa so vgrajeni elementi "neto" modela - maksimiranje kompenzacije (Gabrovec., et al., 2003, str. 78 - 83). Izdelan je bil obračunski sistem, 
po katerem država koncesionarjem plačuje kompenzacijo, ki naj bi pokrila razliko med normiranimi stroški in realiziranimi prihodki. Ker je največja možna izplačana kompenzacija po prevoženem kilometru omejena, prevozniki dejansko nosijo velik del rizika za prihodke. Maksimalna kompenzacija je izračunana na podlagi zagotovljenih proračunskih sredstev in pričakovanega obsega izvajanja JPP $\vee$ kilometrih.

Značilnosti obstoječega sistema so še naslednje:

- država ne pokriva $v$ celoti razlike med priznanimi stroški in realiziranimi prihodki, zato praktično niti ne more »naročati« dodatnih linij;

- vsi koncesionarji imajo enake priznane stroške na vozilo-kilometer;

- med prevozniki (koncesionarji) so velike razlike glede opravljanja tako imenovanih «rentabilnih" in »nerentabilnih" linij;

- nekateri prevozniki (osrednji - severni del Slovenije) beležijo sorazmerno visoke prihodke, ki se približujejo priznanim stroškom;

- drugi (vzhodni del Slovenije) pa pokrivajo izrazito nerentabilne linije. Zaradi omejenega izplačevanja kompenzacij so prevozniki (koncesionarji) $\vee$ neenakopravnem položaju.

- Sistem financiranja dejavnosti GJS je izjemno tog. Zaradi financiranja te dejavnosti iz proračuna RS se ne da mesečno izvajati obračunavanja in prerazporejanja sredstev glede na priznane stroške in prihodke, kajti vsak prevoznik ima svojo koncesijsko pogodbo, svoj FEP (finančni element predobremenitve), ki se ga predvidi pred vsakokratnim podpisom «finančnega aneksa «, dejanska izplačila pa se obračunavajo glede na poročane prihodke.

Iz slike 1 na naslednji strani je razvidno, da praviloma koncesionarji s prihodki ne pokrivajo normiranih priznanih stroškov izvajanja kilometra GJS. Tako na primer pri koncesionarju Veolia transport Dolenjska in Primorska (bivši SAP d.d.) prevladujejo daljinske linije, kjer je zaradi velikega števila prevoženih kilometrov dejanska proizvodna cena na kilometer nižja od normirane in realne izgube prav gotovo niso tako visoke, kot bi bilo moč sklepati iz grafa. Po drugi strani - na primer - ima prevoznik Kam-bus tudi objektivno "srečo«, da posluje na gosto naseljenem območju z velikim povpraševanjem. Manjši prevozniki (skriti v stolpcu »drugi«) praviloma izvajajo majhno število dobro zasedenih linij z odhodi, povezanimi s šolskim poukom ali delovnim časom podjetij ( $v$ bistvu imajo te linije prevladujoče značilnosti posebnega prevoza). 
Janez Blaž, Marko Hočevar

Spreminjanje upravljanja javnega potniškega

prometa v Sloveniji na podlagi avstrijskih izkušenj

Slika 1: Pokritost normiranih oz. priznanih stroškov s prihodki in kompenzacijami po koncesionarjih, stanje 2006

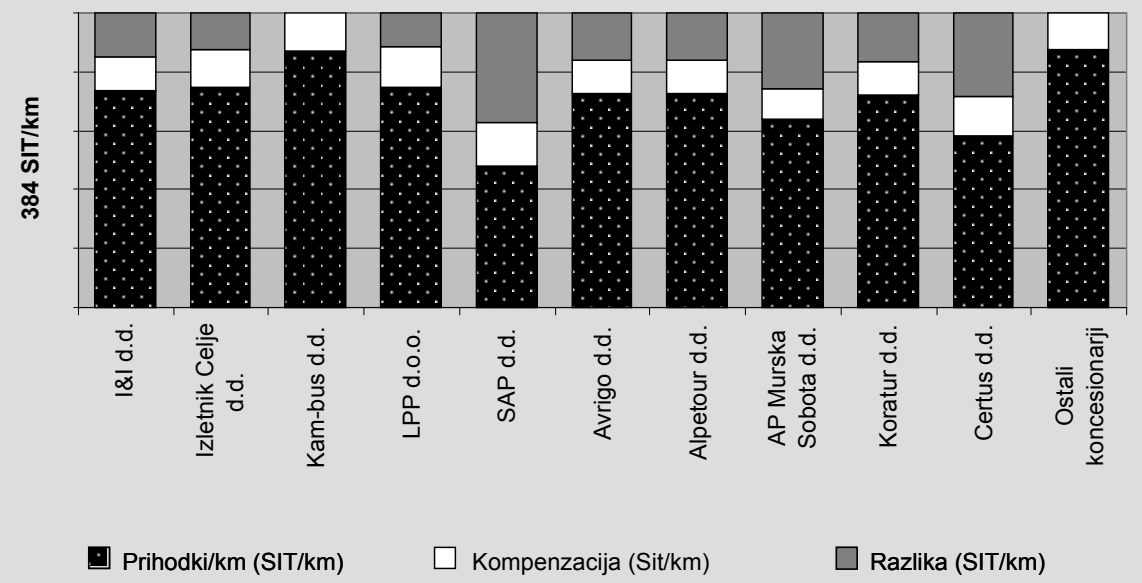

Vir: DRSC (Blaž, Bele, Lep, Đurić 2006)

\section{Primerjalne analize $z$ deželo Štajersko (Avstrija)}

Narejena je primerjava z upravljalcem javnega potniškega cestnega (mestnega in primestnega) in železniškega prometa $v$ deželi Štajerski, to je Štajersko prometno združenje ("Steirische Verkehrsverbund GmbH oz. Styrian transport Association" - STA), ki ima naslednje značilnosti:

- lastnik podjetja "'Štajersko prometno združenje" je dežela Štajerska;

- podjetje ima 13 zaposlenih, njihovi letni stroški znašajo 1,97 mio. euro ( $v$ teh stroških je zajeta oddaja del tujim podjetjem za področje marketinga).

Glavne naloge so:

- prometno upravljanje mestnega in primestnega cestnega in železniškega prometa;

- upravljanje tarifnega sistema in sistema vozovnic;

- raziskava potreb po JPP, informiranje uporabnikov (potnikov); 
Janez Blaž, Marko Hočevar

Spreminjanje upravljanja javnega potniškega prometa v Sloveniji na podlagi avstrijskih izkušenj

- izvajanje kalkulacij, dodeljevanje finančnih sredstev in izvajanje poračunavanja ter kontrola.

Avstrijski sistem ima 3-nivojsko strukturo integriranega javnega potniškega prometa in sicer:

1. nivo je "politični nivo", ki združuje predstavnike mesta Graz, dežele Štajerske in Republike Avstrije na katerem se sprejemajo strateške odločitve o izvajanja JPP;

2. nivo je upravljalec JPP (Štajersko prometno združenje), ki ima z zakonom določena pooblastila na nivoju upravljalca JPP (sklepanje pogodb s prevozniki, operativno izvajanje financiranja sistema, usklajevanje voznih redov, prodaja vozovnic, izvajanje nadzora);

3. nivo - izvedbeni nivo so prevozniki.

Iz primerjalnih analiz učinkovitosti z avstrijskim sistemom se neposredni vidni učinki in sicer:

- Avstrijski integrirani sistem cestnega in železniškega mestnega in primestnega prometa potrebuje 126,9 mio. euro na letnem nivoju, da prepelje 100,4 mio. potnikov;

- Obstoječi slovenski sistem na državnem cestnem (medkrajevnem) in železniškem nivoju skupaj z izvajanim JPP na območju MO Maribor potrebuje 124,4 mio. euro, da prepelje 59,9mio potnikov;

Če obstoječemu slovenskemu sistemu (zgornja alinea) dodamo prevoze na MO LJ in se oceni število prepeljanih potnikov: 44 mio. pomeni da $v$ Sloveniji potrebujemo 161,1 mio. euro, da se prepelje 103,9 mio. potnikov. 
Janez Blaž, Marko Hočevar

Spreminjanje upravljanja javnega potniškega

prometa v Sloveniji na podlagi avstrijskih izkušenj

Tabela 3: Primerjava med državnim in lokalnim delom JPP (cestni in železniški) v Sloveniji in integriranim JPP v Avstriji (mestni in primestni cestni in železniški)

\begin{tabular}{|c|c|c|c|c|c|}
\hline \multirow[t]{2}{*}{$\begin{array}{l}\text { Površina } \\
\text { število prebivalcev } \\
\text { število občin }\end{array}$} & \multicolumn{4}{|c|}{$\begin{array}{l}\text { SLOVENIJA } \\
20.273 \mathrm{~km}^{2} \\
1,99637 \mathrm{mio} . \\
210\end{array}$} & \multirow{2}{*}{\begin{tabular}{|c|} 
AVSTRIJA (Štajerska) \\
\\
$16.000 \mathrm{~km}^{2}$ \\
1,2 mio. \\
535 \\
integrirani primestni \\
(medkrajevni), \\
mestni cestni in \\
železniški promet \\
\end{tabular}} \\
\hline & $\begin{array}{l}\text { cestni primestni, } \\
\text { medkrajevni pot- } \\
\text { niški }\end{array}$ & $\begin{array}{l}\text { železniški } \\
\text { potniški }\end{array}$ & $\begin{array}{l}\text { Mestna } \\
\text { občina } \\
\text { Ljubljana }\end{array}$ & $\begin{array}{l}\text { Mestna } \\
\text { občina } \\
\text { Maribor }\end{array}$ & \\
\hline $\begin{array}{l}\text { Število izvajalcev } \\
\text { javnega pot. prometa }\end{array}$ & $\begin{array}{l}47 \text { avt. podjetij - } \\
\text { koncesionarjev }\end{array}$ & SŽ & LPP & $\begin{array}{c}\text { Veolia } \\
\text { Transport }\end{array}$ & 63 \\
\hline $\begin{array}{l}\text { število zaposlenih v } \\
\text { teh podjetjih }\end{array}$ & - & 717 & 921 & 120 & 4500 \\
\hline število linij & 2200 & 147 & 21 & 20 & 500 \\
\hline število postajališč & 7500 & 266 & 479 & 350 & 6200 \\
\hline $\begin{array}{l}\text { število odhodov } \\
\text { na delovni dan }\end{array}$ & 8000 & 593 & - & - & 13.500 \\
\hline $\begin{array}{l}\text { število prodanih } \\
\text { vozovnic }\end{array}$ & - & 4,3 mio. & - & 500.000 & $\begin{array}{l}10,3 \text { mio. in } 96.000 \\
\text { dijaških vozovnic (pupils) }\end{array}$ \\
\hline Prepeljani potniki & 40 mio. & 14,9 mio. & 89,7 mio. $^{*}$ & 5 mio. & 100,4 mio. \\
\hline \begin{tabular}{|l|} 
Prihodki od \\
prodaje vozovnic \\
\end{tabular} & 33,4 mio. & $21,4 \mathrm{mio}$. & 19,5 mi.o & 2,34 mio. & $\begin{array}{l}44,8 \text { mio. (cost recovering } \\
\text { rate-pod } 50 \% \text { ) }\end{array}$ \\
\hline $\begin{array}{l}\text { Razpoložljiva } \\
\text { finančna sredstva } \\
\text { za pokrivanje } \\
\text { stroškov } \\
\text { izvajanja JPP" }\end{array}$ & $\begin{array}{l}\text { Skupaj: } \\
63,2 \text { mio. } \\
\\
\text {-51,9 mio. - po poročilih } \\
\text { koncesionarjev o } \\
\text { prihodkih od prodaje } \\
\text { vozovnic in javnih virov } \\
\text {-11,3 mio. - dodatna } \\
\text { subvencija s strani } \\
\text { DRSC }\end{array}$ & $\begin{array}{l}\text { Skupaj: } \\
57,1 \text { mio. } \\
\\
\text {-21,4 mio. - prihodki } \\
\text { od prodaje kart } \\
\text {-34,3 mio. - pogodba } \\
\text { z JAŽ̈P } \\
\text { - 1,3 mio. - drugi tržni } \\
\text { prihodki }\end{array}$ & $\begin{array}{l}\text { Skupaj: } \\
36,7 \text { mio. } \\
\text { Subvencija MOL: } \\
4,57 \text { mio. } \\
\end{array}$ & $\begin{array}{l}\text { Skupaj: } \\
\text { 4,1 mio. } \\
\text { Subvencija } \\
\text { MOMB: } \\
\text { 1,38 mio. }\end{array}$ & $\begin{array}{l}\text { Skupaj: } \\
126,9 \text { mio. } \\
\text { 33,3 mio. + 48,8 mio. za } \\
\text { subvencioniranje dijaških } \\
\text { vozovnic+ 44,8 mio. kot } \\
\text { prihodek od prodaje kart; } \\
\text { 33,3 mio. pridobi "Verkehr- } \\
\text { sverbund - "VVS"' iz: } \\
-8,6 \text { mio. Republika Avstrija } \\
\text {-12,5 mio. dežela štajerska } \\
-4,5 \text { mio. mesto Graz } \\
\text {-7,7.mio."ostala posebna } \\
\text { naročila" }\end{array}$ \\
\hline $\begin{array}{l}\text { Struktura pokrivanja } \\
\text { stroškov }\end{array}$ & & & $\begin{array}{l}\text { LPP: vsi } \\
\quad 38,7 n\end{array}$ & $\begin{array}{l}\text { stroški } \\
\text { nio. }\end{array}$ & $\begin{array}{l}\text { Upravljalec JPP ("Verkehr- } \\
\text { sverbund") razdeli } 33,3 \text { mio. } \\
\text { za: } \\
\text {-20,3 mio. za subvencioniranje } \\
\text { vozovnic, } \\
-11 \text { mio. za nerentabilne linije, } \\
-1,1 \text { mio. za marketing, } \\
-0,9 \text { mio. za planiranje in } \\
\text { organizacijo. }\end{array}$ \\
\hline
\end{tabular}

* MO Ljubljana (LPP) uporablja drugačno metodologija štetja potnikov; Vir: Hensle, 2007 podatki SŽ, LPP, DRSC. 


\section{Predlogi prihodnje ureditve javnega potniškega prometa v Sloveniji}

Na Direkciji RS za ceste smo v sodelovanju z Ministrstvom za promet pripravili 2 možni obliki prihodnje ureditve JPP (Pirnat, et al., 2007) in sicer:

- po avstrijskem modelu JPP je bil pripravljen predlog za ustanovitev "Centra za javni potniški promet" ( $v$ nadaljevanju CJPP) , ki bi bil primerljiv delovanju Štajerskega prometnega združenja;

- $\quad$ koncesijski model ureditve JPP.

\subsection{Model centra za javni potniški promet (CJPP)}

Center za javni potniški promet bi bil pravna oseba javnega prava $v$ celoti $v$ lasti Republike Slovenije. Temeljne naloge tega centra bi bile:

- vzpostavitev enotnega (usklajenega) voznega reda;

- vzpostavitev, organizacija in upravljanje sistema enotne vozovnice (upravni sistem, tehnični sistem, finančni sistem);

- predlaganje linij voznih redih ter cen vozovnic;

- zbiranje sredstev, namenjenih javnemu potniškemu prometu (sredstva vozovnic, sredstva državnega in občinskih proračunov, sredstva za šolske prevoze, sredstva gospodarskih družb za prevoze delavcev, sredstva turističnih organizacij za javne prevoze $v$ turistične kraje, drugo) in njihovo upravljanje;

- $\quad$ sklepanje (tudi manjših) pogodb s prevozniki o izvedbi prevozov;

- zagotavljanje racionalnega prevoza potnikov na ustrezni kakovostni ravni.

Prednosti tega modela so naslednje:

- enostavna zagotovitev sistema enotne vozovnice, ki lahko vključuje tudi železniške prevoze;

- velik vpliv države nad zagotavljanjem kakovosti prevoznih storitev na vsem ozemlju RS enako;

- poenotenje cen in tarif;

- center in država imata natančen pregled nad ekonomiko celotnega sistema;

- fleksibilnost sistema, saj ga lahko s kratkimi in majhnimi pogodbami center sproti prilagaja potrebam; 
Janez Blaž, Marko Hočevar

Spreminjanje upravljanja javnega potniškega

prometa v Sloveniji na podlagi avstrijskih izkušenj

- možnost angažiranja sredstev zainteresiranih uporabnikov (turizem, šolski prevozi, delavski prevozi...).

Pomanjkljivosti so naslednje:

- nadzor nad višino kompenzacij, torej državnih pomoči, je težavnejši, ker so nekatere manjše pogodbe sklenjene tudi brez javnega razpisa;

- prehodni režim od ustanovitve centra do zagona celotnega sistema je precej zahteven.

Ekonomska upravičenost vzpostavitve CJPP se kaže še v naslednjem:

- znižali bi se skupni upravljalski stroški;

- na področju železniškega prometa se ob ukinitvi nerentabilnih linij pričakuje znižanje stroškov, saj bi se jih lahko nadomestili z določenimi avtobusnimi prevozi;

- CJPP se bi pogajal s posameznimi prevozniki in za posamezne linije, tako da bi se lahko zmanjšali povprečni stroški na kilometer na avtobusnem medkrajevnem prometu iz sedanjih 1,6 na 1,5. To je cena, po kateri že danes vozijo dobro organizirani prevozniki, ki obenem vlagajo $\vee$ kakovost prevoznih storitev.

- število medkrajevnih javno linijskih avtobusnih kilometrov (glede na razpoložljiva finančna sredstva) bi se lahko znižalo za 5 odstotkov oziroma $2.416 .000 \mathrm{~km}$. Zmanjšanje števila $\mathrm{km}$ ne sme iti na račun slabšanja kakovosti ponudbe, temveč je treba ukiniti neatraktivne linije (praviloma gre za zelo dolge linije) in pa določene medkrajevne linije opredeliti kot mestne oziroma občinske (tu gre predvsem za linije pri velikih mestih: Ljubljana, Maribor, Celje...).

- CJPP bi lahko povečal prihodke, saj bi bil v večji meri fleksibilnejši pri sprejemanju poslovnih odločitev. Javni prevozi (šolski in občinski) se sofinancirajo tudi iz občinskih proračunov in prek Ministrstva za šolstvo in šport. CJPP bi moral znati poiskati ekonomsko upravičenost združevanja javnih virov financiranja in javnih linij v najširšem pomenu. Tam, kjer je interes "zasebnega kapitala" po javno linijskem prometu, bi lahko k sofinanciranju javnih linij CJPP pritegnil tudi privatna sredstva (hoteli, podjetja).

Center za javni potniški promet bi bila pravna oseba javnega prava $v$ celoti $\checkmark$ lasti Republike Slovenije. Temeljne naloge tega centra bi bile podobne kot pri avstrijskemu Štajerskem prometnem združenju (izvajanje upravljalskih nalog na 2. nivoju). 


\subsection{Koncesijski model}

Ta model izhaja iz sedanje zakonske ureditve, ki predvideva koncesije. Temeljni element koncesijskega razmerja je, da prevoznik nosi tveganje povpraševanja po prevoznih storitvah, torej številu potnikov. To pomeni, da je pri oblikovanju razpisnih pogojev treba upoštevati naslednje:

- pogodbena razmerja morajo omogočati ekonomska tveganja na daljše obdobje (8-10 let za avtobusne prevoze, 15 let za železniške);

- koncesijsko območje mora biti dovolj veliko, da omogoča koncesionarju kombinacijo rentabilnih in nerentabilnih linij ter potrebno ekonomijo obsega; idealno bi bilo le eno koncesijsko območje $v$ Sloveniji, saj druge rešitve zelo zapletejo sistem;

- nujna pa je izključna pravica enega prevoznika na določeni liniji, saj bi sicer prišlo do prevzemanja potnikov med koncesionarji, ki bi po različnih voznih redih vozili na isti liniji ali njenem delu;

- razpisne zahteve glede storitev morajo biti določene bolj okvirno in večinoma se mora sam ponudnik odločiti, kako bo organiziral svoje delo;

- državna pomoč mora biti določena vnaprej kot najvišja možna kompenzacija;

- $\quad$ po sklenitvi pogodbe mora biti zagotovljena možnost prilagajati obseg prevoznih storitev dejanskim potrebam.

Prednosti:

- ni potreben podrobnejši nadzor nad ekonomiko poslovanja;

- rešitev omogoča zasebno iniciativo glede kakovosti storitev in nova vlaganja $v$ prevozna sredstva;

- rešitev spodbuja prevoznike, da si prizadevajo pridobiti večje število potnikov;

- postopki podelitve koncesije so enostavnejši, čeprav ekonomsko bolj zapleteni;

- praviloma ni pričakovati težav z državno pomočjo, čeprav tega ni mogoče izključiti zaradi relativno ohlapnega postopka podelitve koncesije.

Pomanjkljivosti:

- zelo težko je oblikovati večje število koncesijskih območij z izključno pravico enega koncesionarja; enostavna rešitev je le ena koncesija za vse območje Slovenije;

- obstaja možnost, da vse koncesije dobi en, finančno velik tuj prevoznik; 
Janez Blaž, Marko Hočevar

Spreminjanje upravljanja javnega potniškega

prometa v Sloveniji na podlagi avstrijskih izkušenj

- $\quad$ sistem enotne vozovnice je enostavno vpeljati le v primeru enega koncesionarja, sicer terja zapleten sistem medsebojnih kompenzacij;

- $\quad$ potreben je natančen nadzor kakovosti storitev koncesionarja;

- manjša fleksibilnost sistema, ki se sicer lahko prilagaja okoliščinam poselitve;

- $\quad$ že pred objavo javnega razpisa je potrebna zelo natančna ekonomska analiza.

\section{Predlog urejanja ekonomskega odnosa s koncesionarji po sklenitvi koncesijske pogodbe}

Pri predlogu urejanja ekonomskih odnosov s koncesionarjem oziroma koncesionarji smo izhajali iz naslednjih izhodišč:

1) med oba partnerja (državo in avtoprevoznikom) naj bo tveganje čim bolj sorazmerno porazdeljeno;

2) pregleden in jasen način urejanja medsebojnega ekonomskega odnosa;

3) relativna enostavnost kontrole poslovanja.

$\checkmark$ koncesijski pogodbi se določi kompenzacija Ministrstva za promet na naslednji način, kot ga prikazuje tabela 4.

\section{Tabela 4: Izračun kompenzacije za leto 2009}

\begin{tabular}{|l|l|}
\hline 1. Stroški goriva & \\
\hline 2. Neposredni stroški brez goriva & \\
\hline 3. SKUPAJ NEPOSREDNI STROšKI $(1+2)$ & \\
\hline 4. Posredni stroški $(\% \times 2)$ & \\
\hline 5. Stroški financiranja + dobiček & \\
\hline 6. SKUPAJ STROšKI $(3+4+5)$ & \\
\hline 7. Prihodki od prodaje vozovnic & \\
\hline 8. Prihodki iz javnih virov (občine, min. za šolstvo itd) & \\
\hline 9. SKUPAJ PRIHODKI $(7+8)$ & \\
\hline 10. KOMPENZACIJA (6-9) & \\
\hline
\end{tabular}

Opomba: Posredni stroški se določijo z odstotkom na neposredne stroške brez goriva, stroški financiranja in dobiček pa so določeni z absolutno številko.

Predpostavimo, da je prevoznikova kalkulacija na km naslednja (glej tabela 5): 
Tabela 5: Izračun LC za leto 2009

\begin{tabular}{|l|c|}
\hline 1. Stroški goriva & 0,4 \\
\hline 2. Neposredni stroški brez goriva & 1,0 \\
\hline 3. SKUPAJ NEPOSREDNI STROšKI $(1+2)$ & 1,3 \\
\hline 4. Posredni stroški $(30 \%$ EURO) & 0,3 \\
\hline 5. Stroški financiranja + dobiček & 0,1 \\
\hline 6. SKUPAJ STROšKI $(3+4+5)$ & 1,7 \\
\hline
\end{tabular}

Lastna cena se praviloma spreminja enkrat na leto, ko so znane spremembe letnih cen posameznih elementov cene. Med letom se lahko lastna cena spremeni, če se je cena posameznega elementa lastne cene spremenila za več kot 20 \% (na primer stroški goriva). Prav tako se lahko lastna cena na novo določi, če je prišlo do spremenjenega povpraševanja oziroma posebnih investicij (na primer uvajanje enotne vozovnice, informiranje itd.). Zaradi kalkulacijskih zmot in spremenjenih količinskih elementov kalkulacije (na primer: prevoženi km avtobusov oziroma voznikov), se lastna cena ne bi spreminjala.

Ob predpostavki, da prevoznik prepelje 40 mio. km in bi ustvaril navedene prihodke $\vee$ tabeli 4 , bi dogovorjeno kompenzacijo izračunali na način, kot je prikazan $\vee$ tabeli 6 .

Tabela 6: Izračun zahtevane kompenzacije za leto 2009

\begin{tabular}{|l|l|}
\hline 1. Stroški goriva & 16.000 .000 \\
\hline 2. Neposredni stroški brez goriva & 40.000 .000 \\
\hline 3. SKUPAJ NEPOSREDNI STROšKI $(1+2)$ & 56.000 .000 \\
\hline 4. Posredni stroški (30\% od 40.000.000) & 12.000 .000 \\
\hline 5. Stroški financiranja + dobiček & 4.000 .000 \\
\hline 6. SKUPAJ STROšKI (3+4+5) & 72.000 .000 \\
\hline 7. Prihodki od prodaje vozovnic & 35.000 .000 \\
\hline 8. Prihodki iz javnih virov (občine, min. za šolstvo itd) & 11.000 .000 \\
\hline 9. SKUPAJ PRIHODKI (7+8) & 46.000 .000 \\
\hline 10. KOMPENZACIJA (6-9) & 26.000 .000 \\
\hline
\end{tabular}


Janez Blaž, Marko Hočevar

Spreminjanje upravljanja javnega potniškega

prometa v Sloveniji na podlagi avstrijskih izkušenj

Predpostavimo, da bo junija 2009 cena goriva za 25 \% večja od izhodiščne cene. To pomeni, da so prevozniki upravičeni do povečanja kompenzacije za (20.000.000 km x 0,1 euro) oz. za 2 mio. euro v letu 2009.

31.12.2009 se lahko na podlagi primerjave cen ugotovi nova - popravljena lastna cena. Predpostavimo, da so se cene neposrednih stroškov brez goriva povečale za $10 \%$. Izračun nove lastne cene in kompenzacije za leto 2010 bi bil takšen (glej tabelo 7):

Tabela 7: Izračun LC za leto 2010

\begin{tabular}{|l|c|}
\hline 1. Stroški goriva & 0,5 \\
\hline 2. Neposredni stroški brez goriva & 1,1 \\
\hline 3. SKUPAJ NEPOSREDNI STROšKI $(1+2)$ & 1,6 \\
\hline 4. Posredni stroški $(30 \% 1$ EURO) & 0,33 \\
\hline 5. Stroški financiranja + dobiček & 0,1 \\
\hline 6. SKUPAJ STROšKI $(3+4+5)$ & 1,93 \\
\hline
\end{tabular}

Na podlagi tega izračuna, se lahko ugotovi kompenzacija za leto 2010, kot jo prikazuje tabela 8 .

Tabela 8: Kompenzacija za leto 2010 (predpostavimo 40.000 .000 km)

\begin{tabular}{|l|l|}
\hline 1. Stroški goriva & 20.000 .000 \\
\hline 2. Neposredni stroški brez goriva & 44.000 .000 \\
\hline 3. SKUPAJ NEPOSREDNI STROšKI (1 + 2) & 64.000 .000 \\
\hline 4. Posredni stroški (30\% od 44.000.000) & 13.200 .000 \\
\hline 5. Stroški financiranja + dobiček & 4.000 .000 \\
\hline 6. SKUPAJ STROšKI (3+4+5) & 81.200 .000 \\
\hline 7. Prihodki od prodaje vozovnic & 35.000 .000 \\
\hline 8. Prihodki iz javnih virov (občine, min. za šolstvo itd) & 11.000 .000 \\
\hline 9. SKUPAJ PRIHODKI (7+8) & 46.000 .000 \\
\hline 10. KOMPENZACIJA (6-9) & 35.200 .000 \\
\hline
\end{tabular}

Marca leta 2010 se izdela obračun poslovanja za leto 2009. Ob predpostavki, da dobiček s stroški financiranja ni presegel dogovorjene postavke (4.000.000), se kompenzacija ne zmanjša, prav tako država ne poveča kompenzacije, če je podjetje doseglo izgubo do 4 mio euro. Poglejmo si takšen primer $v$ tabeli 9. 
Tabela 9: Ustvarjeni poslovni izid prevoznika v letu 2009

\begin{tabular}{|l|c|}
\hline 1. Stroški goriva & 18.000 .000 \\
\hline 2. Neposredni stroški brez goriva & 42.000 .000 \\
\hline 3. SKUPAJ NEPOSREDNI STROšKI $(1+2)$ & 60.000 .000 \\
\hline 4. Posredni stroški (30\% od 42.000.000) & 12.600 .000 \\
\hline 5. SKUPAJ STROšKI (3+4+5) & 72.000 .000 \\
\hline 6. Prihodki od prodaje vozovnic & 40.000 .000 \\
\hline 7. Prihodki iz javnih virov (občine, min. za šolstvo itd) & 8.000 .000 \\
\hline 8. Prihodki kompenzacije (dogovorjena +medletno povečanje) & 28.000 .000 \\
\hline 9. SKUPAJ PRIHODKI & 76.000 .000 \\
\hline 10. Poslovni izid + stroški financiranja (9-5) & 4.000 .000 \\
\hline
\end{tabular}

Opomba: posredne stroške se prizna le z dogovorjenim odstotkom na neposredne stroške brez goriva. Če bi podjetje doseglo izgubo, bi država pokrila tisti del izgube, ki bi presegal 4. mio.

Podobno bi se naredil tudi obračun za leto 2010. Marca 2011 bi bili znani podatki o ustvarjenih prihodkih $v$ letih 2009 in 2010. Če so bili ustvarjeni prihodki leta 2010 manjši od prihodkov iz leta 2009, je prevoznik upravičen do višje kompenzacije za to razliko. Vendar mu povišana kompenzacija ne sme ustvariti večjega dobička od dogovorjenega.

\section{Zaključek}

Glede na sprejeto Resolucijo o prometni politiki Republike Slovenije (Ur.l., 2006), se kažejo nujne spremembe na področju javnega potniškega prometa v Sloveniji. Same spremembe $v$ smislu nadaljnjega razvoja na tem področju so povezane s spremembami na treh področjih: organizacijsko - pravnem, operativno tehničnem in finančnem področju.

Nadaljnji razvoj integriranega (mestnega, medkrajevnega cestnega in železniškega) javnega potniškega prometa $\vee$ Sloveniji je odvisen ne samo od aktivnosti na Ministrstvu za promet, ampak tudi od drugih ministrstev, lokalnih skupnosti oz. preostalih zainteresiranih institucij, ustanov ipd. Z razvojem tega področja se namreč rešujejo ne samo okoljevarstvene zahteve po zmanjšanju emisijskih delcev (Ministrstvo za okolje) ampak se tudi zagotavlja mobilnost 
Janez Blaž, Marko Hočevar

Spreminjanje upravljanja javnega potniškega

prometa v Sloveniji na podlagi avstrijskih izkušenj

različnih struktur potnikov: osnovnošolcev, dijakov (Ministrstvo za šolstvo), delavcev, upokojencev, invalidov (Ministrstvo za delo, družino, socialne zadeve), študentov (Ministrstvo za visoko šolstvo).

Vse to pa zahteva, da se $v$ Sloveniji najprej vzpostavi ustrezna 3-nivojska organizacijska struktura delovanja integriranega javnega potniškega prometa (kot je bilo prikazano s primerjalnimi analizami z Avstrijo) in sicer na političnem, upravljalskem in izvajalskem nivoju.

Dr. Marko Hočevar je redni profesor za računovodstvo na Ekonomski fakulteti v Ljubljani. Raziskovalno se ukvarja s problematiko menadžerskega odločanja in oblikovanjem računovodskih informacij za potrebe odločanja. Je avtor oziroma soavtor številnih raziskav s področja ekonomike javnega potniškega prometa.

Mag. Janez Blaž je po osnovni izobrazbi univerzitetni diplomirani inženir strojništva, magistrski študij pa je zaključil na Ekonomsi fakulteti v Ljubljani. Od leta 1996 je zaposlen na Direkciji RS za ceste, leta 2002 pa je prevzel vodenje Sektorja za cestne prevoze. $Z$ imenovanjem ministra za promet je član ožje delovne skupine za pripravo rešitev prihodnje ureditve JPP. Kot vodja sektorja za cestne prevoze je odgovoren za koncesijske pogodbe med koncedentom - Direkcijo RS za ceste in avtobusnimi prevozniki-koncesionarji. 


\section{Literatura in viri}

- $\quad$ Blaž, J., Bele, J., Lep, M., Đurič, A.(2006): Perspektive javnega potniškega cestnega prometa v Sloveniji, Slovenski kongres o cestah in prometu, Portorož, oktober 2006.

- Gabrovec, M., Lep, M., Kotar, M.(2003): Določitev koncesijskih območij, vrednotenje avtobusnih linij in oblikovanje paketov linij, ki bodo predmet gospodarske javne službe, poročilo za Ministrstvo za promet, Ljubljana, junij 2003.

- Hensle, A.(2007): Cooperating and integration of public passenger transport in Austria, Steirische Verkehrsverbund Gmbh, Graz.

- Hočevar, M.(2006): Kalkulacije troškova u uslužnom poduzeću, Računovodstvo i kontroling u postizanju uspješnosti poslovanja, Zagreb - Bol na Braču, lipanj 2006.

- Hočevar, M.(2007): Kalkulacije stroškov v storitvenih podjetjih - primer javnega (potniškega) prometa, 30. Simpozij o sodobnih metodah v računovodstvu, financah in reviziji, Portorož, april 2007.

- $\quad$ Pirnat, R., Blaž, J., Lep, M., Hočevar, M.(2007): Nove oblike podeljevanja storitev v JPP Postavitev centra za JPP in uvedba enotne vozovnice, neobjavljeno gradivo, Ljubljana.

- Resolucija o prometni politiki Republike Slovenije, Uradni list št.: 58/2006 
Janez Blaž, Marko Hočevar

Spreminjanje upravljanja javnega potniškega

prometa v Sloveniji na podlagi avstrijskih izkušenj

SUMMARY

\section{CHANGING THE MANAGEMENT OF PUBLIC PAS- SENGER TRANSPORT IN SLOVENIA ON THE BASIS OF THE AUSTRIAN EXPERIENCE}

The Roads Directorate of the Republic of Slovenia (DRSC), a body within the Ministry of Transport, is the operator of public interurban road transport in Slovenia. As a public transport authority (PTA) it has awarded 47 concession contracts to various bus operators - concessionaires.

The paper first sets out the current state in this field and the existing relations between the PTA and concessionaires in Slovenia in terms of coordinating timetables, adding and cancelling buses, providing funds, and other elements of concession contracts.

The number of running kilometres in public passenger transport (PPT) is decreasing. In 2004 the providers made 51,5 million $\mathrm{km}$, in $2005-49,5$ million km, in 2006 - 47,7 million km, and in 2007 - 46,2 million km.

The main problem are lines which are not economically justifiable, which the providers then cancel. Consequently, the inhabitants in such sparsely populated areas are forced to find alternative solutions, i.e. their own means of transport. In the near future, the current trend should be reversed into one of increase.

Along with the decrease in the running kilomerers the number of passenger decreases as well. The analysis of the passenger structure shows that approx $60-70 \%$ of passengers in Slovenia are pupils (people without a driving licence). There is only a very small percentage of occasional passengers.

Some providers in certain parts of Slovenia have put a lot of effort into making PPT as attractive as possible. As a result, these providers cover their costs by the income from tickets and do not need any additional subsidies.

On the basis of these experiences the future regulation should incorporate a system of stimulation for providers increasing the number of passengers.

The analysis shows that the providers who run long-distance lines have lower incomes but also lower costs, and that among 45 providers 
who run PPT at the moment there are big differences as to their incomes and costs.

The political decision about the most appropriate organisational form of the integrated PPT (integrating urban, suburban and interurban rail and road public transport) is still under discussion.

An entirely new three-level organisational model is in preparation:

- the state level (the main tasks are: new legislation, a new system of financing PPT, which should be transparent; regulation acts should stipulate that the relation between the available public money and the extent of PPT needed be optimised)

- the level of the PTA (the main tasks are: monitoring the need for PPT, providing funds for the providers of PPT, supervision, cooperating with local communities and other institutions interested in PPT)

- the level of the providers of PPT (the main task is to provide PPT; other tasks are: ensuring the quality and punctuality of their services and improving their services, e.g. suggesting new lines)

A comparative analysis with the Austrian system of integrated urban and interurban public road and rail passenger transport is also presented, primarily in terms of PPT effectiveness expressed as a relation between the number of passengers transported and available funds. The threelevel organisational model for integrated PPT in Austria and the systemic division of responsibilities and competencies throughout those levels is described.

The paper then sets out the Roads Directorate's activities within the Ministry of Transport relating to the future organisation of PPT after 2009 when the existing concession contracts in this field expire. 